\title{
Non-Steroidal Anti-Inflammatory Drug Use and the Risk of Parkinson's Disease
}

\author{
Angelika D. Manthripragada ${ }^{a}$ Eva S. Schernhammer ${ }^{a, c, d}$ Jiaheng Qiu ${ }^{b}$ \\ Soren Friis ${ }^{\mathrm{e}}$ Lene Wermuth $^{f}$ Jorgen H. Olsen ${ }^{\mathrm{e}}$ Beate Ritz ${ }^{\mathrm{a}}$ \\ Departments of a Epidemiology and ${ }^{b}$ Biostatistics, School of Public Health, UCLA, Los Angeles, Calif., \\ 'Channing Laboratory, Department of Medicine, Brigham and Women's Hospital and Harvard Medical School, \\ and ${ }^{\mathrm{d}}$ Department of Epidemiology, Harvard School of Public Health, Boston, Mass., USA; ${ }^{\mathrm{e}}$ Institute of Cancer \\ Epidemiology, Danish Cancer Society, Copenhagen, and fDepartment of Neurology, Odense University Hospital, \\ Odense, Denmark
}

\section{Key Words}

Parkinson's disease $\cdot$ Case-control study $\cdot$

Anti-inflammatory drugs

\begin{abstract}
Background: Experimental evidence supports a preventative role for non-steroidal anti-inflammatory drugs (NSAIDs) in Parkinson's disease (PD). Methods: We investigated associations between use of aspirin, nonaspirin NSAIDs, and acetaminophen and PD in a large population-based casecontrol study using Danish health and pharmacy registries. We identified 1,931 PD cases reported in hospital or outpatient clinic records who had received a primary diagnosis of PD between 2001 and 2006, and 9,651 age- and sex-matched controls from the Danish population register. Prescription medication use was documented in a pharmacy database covering all residents of Denmark since 1995. Results: Adjusting for age, sex, use of cardiovascular disease drugs, diagnosis of chronic pulmonary obstructive disorder, and Charlson comorbidity scores, and excluding prescriptions filled within 5 years before diagnosis, we found no evidence for an association between PD and either aspirin use (OR = $0.97 ; 95 \% \mathrm{Cl} 0.82,1.14)$ or nonaspirin NSAID use (OR $=0.97$;
\end{abstract}

$95 \% \mathrm{Cl} 0.86,1.09)$, regardless of intensity of use; further, there was no association between use of ibuprofen or acetaminophen and PD. Conclusion: Our findings provide no evidence for a protective effect of nonaspirin and aspirin NSAID prescription drug use shortly before PD onset.

Copyright $\odot 2011$ S. Karger AG, Basel

\section{Introduction}

Inquiries into the role of neuroinflammation in Parkinson's disease (PD) have coincided with increasing interests in determining whether anti-inflammatory medications may be helpful in preventing PD. Today, it is well documented that neuroinflammatory processes contribute to the etiology of PD $[1,2]$. Experimental evidence and animal models in particular support a preventative role for nonsteroidal anti-inflammatory drugs (NSAIDs) in PD. For example, studies have demonstrated that anti-inflammatory drugs such as acetylsalicylic acid are protective against MPTP-induced striatal dopamine depletion in mice $[3,4]$. However pharmacoepidemiologic evidence remains equivocal; in fact, even two recent meta-analyses summarizing all published data report

\section{KARGER}

(c) 2011 S. Karger AG, Basel

Fax +41613061234 E-Mail karger@karger.ch www.karger.com
Accessible online at: www.karger.com/ned
Beate Ritz, MD, PhD

Department of Epidemiology, UCLA School of Public Health, Box 951772

650 Charles E. Young Drive

Los Angeles, CA 90095-1772 (USA)

Tel. +1 310206 7458, E-Mail britz@ucla.edu 
different conclusions $[5,6]$. The first meta-analysis concluded that ibuprofen may be protective but NSAIDs as a class likely do not modify the risk of PD [6], while the second meta-analysis, which used more restrictive inclusion criteria, stated that 'regular and long-term use' of non-aspirin NSAIDs reduces PD risk [5]. The uncertainty regarding a possible neuroprotective role for NSAIDs as a class or ibuprofen alone stems in large part from differences in how previous human studies grouped or ascertained their data, since medication type, timing of use prior to disease onset, and overall dose may be critical for assessing and interpreting their results. In order to address some of these previous study limitations, we conducted a large population-based case-control study based within the Danish registry that allowed us to ascertain a largely complete record of prescription NSAID and aspirin use (including dose and duration of use) nationwide in Denmark starting in 1995.

\section{Methods}

\section{Study Population}

Denmark's National Health Service provides free and equal access healthcare to its residents. Each health services-related event is recorded in relevant national databases, including the Danish Hospital Register and the Danish Registry of Medical Products Statistic (the national prescription database). Both of these databases can be linked to the Danish Central Population Registry using a unique personal identification number assigned to all Danish citizens at birth or when awarded citizenship.

We conducted a population-based case control study using this registry system. Cases were ascertained from the Danish Hospital Register that registered all hospitalizations with a PD diagnosis since 1977 and all clinic visits, including outpatient clinics, since 1994 . We identified a total of 82,140 subjects, which comprised 13,695 cases who had received a primary PD diagnosis in the Danish Hospital Register in the period 1986-2006 and (1) had a valid personal identification number; (2) were over 35 years of age at the time of diagnosis, and (3) had not emigrated from Denmark, along with their 68,445 matched controls. To allow for a sufficiently long lag time between aspirin/NSAID medication use and PD diagnosis, we restricted the participants to all cases (and their matched controls) registered for the first time with a primary diagnosis of PD (International Classification of Diseases, 10th revision, code G20) between January 2001 and December 2006. In order to identify the earliest possible date of a PD diagnosis among these participants, we further refined the date of primary diagnosis of PD back to the first hospital or outpatient record that mentioned $\mathrm{PD}$ or the first recorded prescription of a PD medication (anatomical therapeutic chemical, ATC, code N04B) since inception of the national prescription database (1995), whichever occurred earlier. If the backdated diagnosis (index) date occurred before 2001, the cases and their matched (5 or less) controls were excluded. This resulted in 13,123 total subjects (2,188 cases and 10,935 controls). We also excluded PD patients who had never received a PD drug prescription (ATC N04 AA0104, BA02-03, BB01, BC01-06, BD01-02, BX01-02), i.e. 257 cases and their respective 1,284 matched controls (1,541 total subjects), leaving us with a final total of 11,582 subjects (1,931 PD cases, 9,651 controls). In sensitivity analyses, aimed at limiting the potential for diagnostic bias, we excluded PD cases (and these cases' matched controls) and controls diagnosed with any type of dementia (both Alzheimer type and unspecified) or cerebrovascular disease before the index date (305 cases, 2,282 controls) or patients having taken neuroleptic medications (ATC N05A) within half a year of diagnosis (194 cases).

\section{Drug Use}

Since 1995, the national prescription database has received data on dispensed prescriptions from all pharmacies in the country. Available data include the individual's personal identification number, drug type by ATC code, and prescription dispensing date. All nonaspirin NSAIDs, except low-dose ibuprofen (200-mg tablets), can only be obtained with a prescription in Denmark. Over-the-counter ibuprofen use is estimated to account for $14 \%$ of total usage [7]. Aspirin and acetaminophen can be obtained over the counter, but because costs for prescribed medications are at least partially reimbursed, long-term usage is thought to be largely confined to prescriptions and therefore captured in the national prescription database [8].

For each study subject, we identified all prescriptions of aspirin (ATC codes B01AC06, N02BA01, N02BA51), nonaspirin NSAIDs (ATC group M01A), and acetaminophen (ATC code N02BE01) dispensed from 1995 until the index date. Because of the long preclinical period of PD, estimated to be 5-7 years [9], and because our case identification methods, despite our efforts to reduce this possibility likely still ascertained prevalent PD cases, we advanced the index date (lagged) by 5 years for both cases and their matched controls in our primary analysis. Participants were defined as 'ever' users of the medications of interest if 2 or more prescriptions were recorded for them in the pharmacy database during the relevant period of time and as nonusers otherwise. Among users, we also created a variable for average annual use, which was the sum of the total number of prescriptions divided by years of use prior to the index date.

\section{Statistical Analysis}

We used unconditional logistic regression to calculate $95 \%$ confidence intervals (CI) and odds ratios (OR) for the following groups: aspirin, all nonaspirin NSAIDs, ibuprofen, and acetaminophen. Acetaminophen, a common pain reliever that is not an NSAID, was included to assess whether potential associations reflected a nonspecific effect of analgesics. Analyses for average annual use were based on the following four categories: less than 1 prescription per year on average (reference group); 1-2 prescriptions; $>2-3$ prescriptions, and $3+$ prescriptions on average per year. In sensitivity analyses, we distinguished between aspirin prescribed in low dose (75-100 $\mathrm{mg}$ ) as an anticoagulant or for the prevention of cardiovascular disease (ATC code B01AC06) and aspirin prescribed as a pain killer (ATC codes N02BA01, N02BA51). We adjusted for age at diagnosis (continuous), sex, comorbidities registered before the lagged index date (using the Charlson index, a weighted index based on ICD codes for 19 chronic disease categories that takes into account the number and seriousness of comorbid diseases) [10], chronic obstructive pul- 
Table 1. Characteristics of the Danish study population, 2001-2006

\begin{tabular}{|c|c|c|c|c|c|c|}
\hline & \multicolumn{3}{|c|}{ Cases $(n=1,931)$} & \multicolumn{3}{|c|}{ Controls $(\mathrm{n}=9,651)$} \\
\hline & total & $\begin{array}{l}\text { males } \\
(\mathrm{n}=1,121)\end{array}$ & $\begin{array}{l}\text { females } \\
(\mathrm{n}=810)\end{array}$ & total & $\begin{array}{l}\text { males } \\
(\mathrm{n}=5,603)\end{array}$ & $\begin{array}{l}\text { females } \\
(\mathrm{n}=4,048)\end{array}$ \\
\hline Age groups $^{\mathrm{a}}$ & 1,931 & $71.9 \pm 10.8^{1}$ & $72.6 \pm 10.2^{1}$ & 9,651 & $71.9 \pm 10.8^{1}$ & $72.6 \pm 10.2^{1}$ \\
\hline $30-40$ & 15 & $10(0.9)$ & $5(0.6)$ & 68 & $45(0.8)$ & $23(0.6)$ \\
\hline $40-50$ & 59 & $39(3.5)$ & $20(2.5)$ & 298 & $194(3.5)$ & $104(2.6)$ \\
\hline $50-60$ & 183 & $109(9.7)$ & $74(9.1)$ & 921 & $548(9.8)$ & $373(9.2)$ \\
\hline $60-70$ & 438 & $258(23.0)$ & $180(22.2)$ & 2,190 & $1,309(23.4)$ & $881(21.8)$ \\
\hline $70-80$ & 753 & $420(37.5)$ & $333(41.1)$ & 3,769 & $2,100(37.5)$ & $1,669(41.2)$ \\
\hline $80-90$ & 455 & $274(24.4)$ & $181(22.3)$ & 2,279 & $1,356(24.2)$ & $923(22.8)$ \\
\hline$>90$ & 28 & $11(1.0)$ & $17(2.1)$ & 126 & $51(0.9)$ & $75(1.9)$ \\
\hline \multicolumn{7}{|c|}{ Charlson index ${ }^{\mathrm{b}}$} \\
\hline 0 & 1,454 & $828(73.9)$ & $626(77.3)$ & 7,365 & $4,215(75.2)$ & $3,150(77.8)$ \\
\hline 1 & 251 & $163(14.5)$ & $88(10.9)$ & 1,245 & $791(14.1)$ & $454(11.2)$ \\
\hline$\geq 2$ & 226 & $130(11.6)$ & $96(11.9)$ & 1,041 & $597(10.7)$ & $444(11.0)$ \\
\hline \multicolumn{7}{|c|}{ COPD diagnosis ${ }^{\mathrm{b}}$} \\
\hline No & 1,910 & $1,108(98.8)$ & $802(99.0)$ & 9,448 & $5,473(97.7)$ & $3,975(98.2)$ \\
\hline Yes & 21 & $13(1.2)$ & $8(1.0)$ & 203 & $130(2.3)$ & $73(1.8)$ \\
\hline \multicolumn{7}{|l|}{ CVD drugs ${ }^{\mathrm{b}}$} \\
\hline No & 1,393 & $812(72.4)$ & $581(71.7)$ & 7,269 & $4,249(75.8)$ & $3,020(74.6)$ \\
\hline Yes & 538 & $309(27.6)$ & $229(28.3)$ & 2,382 & $1,354(24.2)$ & $1,028(25.4)$ \\
\hline
\end{tabular}

Values are numbers of cases or controls with percentages in parentheses, unless otherwise specified.

${ }^{1}$ Mean age \pm SD, years. ${ }^{a}$ Age at diagnosis for cases. ${ }^{b}$ Lagged by 5 years; categories represent test scores.

monary disease (COPD) diagnosis (ICD codes = J42, J43, J44 and 490.00, 491.00, 491.01, 491.03) identified in the Danish Hospital Register, and the use of cardiovascular disease drugs (ATC codes B01AA03, B01AA04, C01A-D, C07, C08, C09A-D) identified from the national prescription database prior to the lagged index date. We lagged both the Charlson index and COPD by 5 years to capture the general health status of subjects at the time of the lagged index date. A diagnosis of COPD was used as a proxy for a history of heavy smoking. The Danish population is primarily Caucasian, thus we did not adjust for race/ethnicity. We also stratified some analyses by age at first diagnosis $(<60, \geq 60$ years) and sex. To further explore the possibility that NSAID use was triggered by early symptoms of PD, in addition to our primary analyses based on a 5-year lag period, we also performed unlagged and 2-year lagged analyses.

\section{Results}

As shown in table 1, our study population was mostly (58\%) male, and on average 72.2 years (standard deviation, SD, 10.5) of age. Approximately a quarter of cases and controls scored above zero on the Charlson index 5 years prior to PD diagnosis (24.7 vs. $23.7 \%$ ), and $24.7 \%$ of controls and $27.9 \%$ of cases had been prescribed medica- tions for cardiovascular diseases, while COPD diagnoses were - as expected - somewhat higher in controls (2.1 vs. $1.1 \%$ in cases). Before the index date, $34.6 \%$ of our study population had ever received two or more prescriptions for nonaspirin NSAIDs and 27.3\% for aspirin (19\% prescribed as a low-dose anticoagulant and $12.1 \%$ as a pain killer). The recorded median length of time subjects received non-aspirin NSAID prescriptions prior to the index date was 4.5 years (SD, 4.6) for PD cases and 4.9 years $(\mathrm{SD}, 4.9)$ for controls; and for aspirin it was 3.7 years (SD, 2.9) among $\mathrm{PD}$ cases and 4.0 years $(\mathrm{SD}, 2.9)$ among controls.

Although we did not see an association between 5-year lagged prediagnosis aspirin use and PD (table 2) among all subjects combined $(\mathrm{OR}=0.97 ; 95 \%$ CI $0.82,1.14)$, our data suggested a $22 \%$ risk reduction $(\mathrm{OR}=0.78 ; 95 \% \mathrm{CI}$ $0.59,1.04)$ for aspirin use in women. This inverse association between aspirin use and PD was strongest in women using an annual average of 2 or more aspirin prescriptions but all 95\% CI included the null value. Additionally, low-dose aspirin prescribed as an anticoagulant showed an inverse association with PD risk among women $(\mathrm{OR}=0.69 ; 95 \%$ CI $0.48,0.99)$. However, when exclud- 
Table 2. Association between aspirin use and PD, 5-year lag ${ }^{\mathrm{a}}$

\begin{tabular}{|c|c|c|c|c|}
\hline $\begin{array}{l}\text { Cases } \\
(\mathrm{n}=1,931)\end{array}$ & \multicolumn{2}{|c|}{$\begin{array}{l}\text { Controls } \\
(\mathrm{n}=9,651)\end{array}$} & \multirow[t]{2}{*}{ OR } & \multirow[t]{2}{*}{$95 \% \mathrm{CI}$} \\
\hline $\mathrm{n}$ & $\mathrm{n}$ & $\%$ & & \\
\hline
\end{tabular}

Total population $(n=11,582)$

\begin{tabular}{|c|c|c|c|c|c|c|}
\hline \multicolumn{7}{|l|}{ Ever $\mathrm{u}$} \\
\hline No & 1,692 & 87.6 & 8,518 & 88.3 & 1.0 (ref.) & \\
\hline Yes & 239 & 12.4 & 1,133 & 11.7 & 0.97 & $0.82,1.14$ \\
\hline \multicolumn{7}{|c|}{ Average annual prescriptions } \\
\hline$<1$ & 1,743 & 90.3 & 8,714 & 90.3 & 1.0 (ref.) & \\
\hline 1 to $<2$ & 52 & 2.7 & 269 & 2.8 & 0.87 & $0.64,1.21$ \\
\hline 2 to $<3$ & 44 & 2.3 & 229 & 2.4 & 0.86 & $0.62,1.21$ \\
\hline$\geq 3$ & 92 & 4.8 & 439 & 4.6 & 0.94 & $0.74,1.20$ \\
\hline
\end{tabular}

Males $(n=6,724)$

Ever use

$\begin{array}{lrrrrlll}\text { No } & 956 & 85.3 & 4,888 & 87.2 & 1.0 \text { (ref.) } \\ \text { Yes } & 165 & 14.7 & 715 & 12.8 & 1.09 & 0.89,1.35 \\ \begin{array}{l}\text { Average annual prescriptions } \\ <1\end{array} & 992 & 88.5 & 5,006 & 89.3 & 1.0 \text { (ref.) } & \\ 1 \text { to }<2 & 31 & 2.8 & 167 & 3.0 & 0.84 & 0.57,1.26 \\ 2 \text { to }<3 & 31 & 2.8 & 149 & 2.7 & 0.96 & 0.64,1.43 \\ \geq 3 & 67 & 6.0 & 281 & 5.0 & 1.08 & 0.80,1.45\end{array}$

Females $(n=4,858)$

Ever use

\begin{tabular}{lrrrrll} 
No & 736 & 90.9 & 3,630 & 89.7 & 1.0 (ref.) & \\
Yes & 74 & 9.1 & 418 & 10.3 & 0.78 & $0.59,1.04$ \\
verage annual prescriptions & & & & \\
$<1$ & 751 & 92.7 & 3,708 & 91.6 & 1.0 (ref.) & \\
1 to $<2$ & 21 & 2.6 & 102 & 2.5 & 0.92 & $0.56,1.49$ \\
2 to $<3$ & 13 & 1.6 & 80 & 2.0 & 0.71 & $0.39,1.30$ \\
$\geq 3$ & 25 & 3.1 & 158 & 3.9 & 0.71 & $0.46,1.10$ \\
\hline
\end{tabular}

a Adjusting for age, sex, 5-year lagged COPD, 5-year lagged use of CVD drugs, and 5-year lagged Charlson index.
Table 3. Association between nonaspirin NSAID use and PD, 5-year lag

\begin{tabular}{|c|c|c|c|c|}
\hline $\begin{array}{l}\text { Cases } \\
(\mathrm{n}=1,931)\end{array}$ & \multicolumn{2}{|c|}{$\begin{array}{l}\text { Controls } \\
(\mathrm{n}=9,651)\end{array}$} & \multirow[t]{2}{*}{$\mathrm{OH}$} & \multirow[t]{2}{*}{$95 \% \mathrm{CI}$} \\
\hline $\mathrm{n}$ & $\mathrm{n}$ & $\%$ & & \\
\hline
\end{tabular}

\begin{tabular}{|c|c|c|c|c|c|c|}
\hline \multicolumn{7}{|c|}{ Total population $(n=11,582)$} \\
\hline No & 1,499 & 77.6 & 7,467 & 77.4 & ref. & \\
\hline Yes & 432 & 22.4 & 2,184 & 22.6 & 0.97 & $0.86,1.09$ \\
\hline \multicolumn{7}{|c|}{ Average annual use } \\
\hline$<1$ & 1,678 & 87.0 & 8,415 & 87.2 & ref. & \\
\hline 1 to $<2$ & 2105 & 5.4 & 581 & 6.0 & 0.90 & $0.73,1.11$ \\
\hline 2 to $<3$ & 60 & 3.1 & 254 & 2.6 & 1.18 & $0.89,1.57$ \\
\hline$\geq 3$ & 88 & 4.6 & 401 & 4.2 & 1.08 & $0.85,1.37$ \\
\hline
\end{tabular}

\begin{tabular}{|c|c|c|c|c|c|c|}
\hline \multicolumn{7}{|c|}{ Males $(n=6,724)$} \\
\hline \multicolumn{7}{|l|}{ Ever use } \\
\hline No & 892 & 79.6 & 4,485 & 80.0 & ref. & \\
\hline Yes & 229 & 20.4 & 1,118 & 20.0 & 1.01 & $0.86,1.19$ \\
\hline \multicolumn{7}{|c|}{ Average annual use } \\
\hline$<1$ & 991 & 88.4 & 5,004 & 89.3 & ref. & \\
\hline 1 to $<2$ & 62 & 5.5 & 308 & 5.5 & 1.01 & $0.76,1.34$ \\
\hline 2 to $<3$ & 30 & 2.7 & 128 & 2.3 & 1.16 & $0.77,1.73$ \\
\hline$\geq 3$ & 38 & 3.4 & 163 & 2.9 & 1.16 & $0.81,1.66$ \\
\hline
\end{tabular}

\begin{tabular}{|c|c|c|c|c|c|c|}
\hline \multicolumn{7}{|c|}{ Females $(n=4,858)$} \\
\hline \multicolumn{7}{|l|}{ Ever use } \\
\hline No & 607 & 74.9 & 2,982 & 73.7 & ref. & \\
\hline Yes & 203 & 25.1 & 1,066 & 26.3 & 0.93 & $0.78,1.10$ \\
\hline \multicolumn{7}{|c|}{ Average annual use } \\
\hline$<1$ & 687 & 84.8 & 3,411 & 84.3 & ref. & \\
\hline 1 to $<2$ & 43 & 5.3 & 273 & 6.7 & 0.77 & $0.55,1.08$ \\
\hline 2 to $<3$ & 30 & 3.7 & 126 & 3.1 & 1.20 & $0.79,1.80$ \\
\hline$\geq 3$ & 50 & 6.2 & 238 & 5.9 & 1.02 & $0.74,1.41$ \\
\hline
\end{tabular}

a Adjusting for age, sex, 5-year lagged COPD, 5-year lagged cardiovascular disease, and 5-year lagged Charlson index.

for ibuprofen by gender and no trend with increasing dose (table 4).

In unlagged analyses, we noted a statistically significant positive association for ever use of prescription aspirin and $\mathrm{PD}$ overall $(\mathrm{OR}=1.20 ; 95 \% \mathrm{CI} 1.07,1.34)$ which did not appear to differ by gender (male: $\mathrm{OR}=1.11 ; 95 \%$ CI 0.95, 1.30; female: $\mathrm{OR}=1.35$; $95 \% \mathrm{CI} 1.12,1.62$ ). Moreover, unlagged analyses revealed slightly increased OR for ever use of nonaspirin NSAIDs (OR $=1.17$; 95\% CI $1.06,1.29)$, ibuprofen (OR $=1.14 ; 95 \% \mathrm{CI} 1.01,1.28)$, and acetaminophen $(\mathrm{OR}=1.47 ; 95 \% \mathrm{CI} 1.30,1.66)$.

Our results did not measurably change when excluding cases and controls diagnosed with dementia or cerebrovascular disease before the index date, or when ex- 
Table 4. Association between ibuprofen use and PD, 5-year laga

\begin{tabular}{lllll}
\hline $\begin{array}{llll}\text { Cases } \\
(\mathrm{n}=1,931)\end{array}$ & & $\begin{array}{l}\text { Controls } \\
(\mathrm{n}=9,651)\end{array}$ & OR & $95 \% \mathrm{CI}$ \\
\cline { 2 - 2 } $\mathrm{n} \quad \%$ & & $\mathrm{n} \quad \%$ & \\
\hline
\end{tabular}

\begin{tabular}{|c|c|c|c|c|c|c|}
\hline \multicolumn{7}{|c|}{ Total population $(n=11,582)$} \\
\hline \multicolumn{7}{|c|}{ Ever use } \\
\hline No & 1,736 & 89.9 & 8,711 & 90.3 & ref. & \\
\hline Yes & 195 & 10.1 & 940 & 9.7 & 1.03 & $0.88,1.22$ \\
\hline \multicolumn{7}{|c|}{ Average annual prescriptions } \\
\hline$<1$ & 1,825 & 94.5 & 9,185 & 95.2 & ref. & \\
\hline 1 to $<2$ & 47 & 2.4 & 224 & 2.3 & 1.05 & $0.76,1.44$ \\
\hline 2 to $<3$ & 20 & 1.0 & 99 & 1.0 & 1.02 & $0.62,1.64$ \\
\hline$\geq 3$ & 39 & 2.0 & 143 & 1.5 & 1.35 & $0.94,1.93$ \\
\hline
\end{tabular}

\begin{tabular}{|c|c|c|c|c|c|c|}
\hline \multicolumn{7}{|c|}{ Males $(n=6,724)$} \\
\hline \multicolumn{7}{|l|}{ Ever use } \\
\hline No & 1,019 & 90.9 & 5,131 & 91.6 & ref. & \\
\hline Yes & 102 & 9.1 & 472 & 8.4 & 1.07 & $0.86,1.35$ \\
\hline \multicolumn{7}{|c|}{ Average annual prescriptions } \\
\hline$<1$ & 1,063 & 94.8 & 5,377 & 96.0 & ref. & \\
\hline 1 to $<2$ & 29 & 2.6 & 122 & 2.2 & 1.18 & $0.78,1.79$ \\
\hline 2 to $<3$ & 11 & 1.0 & 49 & 0.9 & 1.12 & $0.58,2.16$ \\
\hline$\geq 3$ & 18 & 1.6 & 55 & 1.0 & 1.64 & $0.96,2.81$ \\
\hline
\end{tabular}

Females $(n=4,858)$

Ever use

$\begin{array}{lrrrrll}\text { No } & 717 & 88.5 & 3,580 & 88.4 & \text { ref. } & \\ \text { Yes } & 93 & 11.5 & 468 & 11.6 & 0.99 & 0.78,1.25 \\ \text { Average annual prescriptions } & & & & \\ <1 & 762 & 94.1 & 3,808 & 94.1 & \text { ref. } & \\ 1 \text { to }<2 & 18 & 2.2 & 102 & 2.5 & 0.88 & 0.53,1.46 \\ 2 \text { to }<3 & 9 & 1.1 & 50 & 1.2 & 0.90 & 0.44,1.85 \\ \geq 3 & 21 & 2.6 & 88 & 2.2 & 1.17 & 0.72,1.90\end{array}$

a Adjusting for age, sex, 5-year lagged COPD, 5-year lagged cardiovascular disease, and 5-year lagged Charlson index.

cluding PD patients who took neuroleptic medications (ATC N05A) within half a year of diagnosis. Additionally stratified analyses by age at first diagnosis showed no difference in the effect estimates for any of the medication groups.

\section{Discussion}

Our findings in this large Danish population-based case-control study provide little evidence for a protective role of prescription nonaspirin or aspirin NSAID use, or ibuprofen use, during a short preclinical period prior to PD diagnosis. The only statistically significant inverse as- sociation with PD risk we observed was for women prescribed low-dose aspirin as anticoagulants $(\mathrm{OR}=0.69$; $95 \%$ CI $0.48,0.99$ ). Low-dose aspirin has been shown to be able to inhibit mammalian innate immune-mediated responses [11]. Although experimental models show that aspirin has neuroprotective properties [12], two recent meta-analyses did not find any evidence of a protective effect of aspirin use prior to PD onset $[5,6]$. While aspirin is available over the counter in Denmark, long-term use is thought to be largely confined to prescriptions [8]. Thus, we likely captured only long-term aspirin users in these prescription data.

We also did not find an inverse association between nonaspirin NSAID use and PD, even among users with higher average annual use. This is inconsistent with results of a recent meta-analysis suggesting that longerterm and regular nonaspirin NSAID users might be protected. Nonaspirin NSAIDs have heterogeneous pharmacological properties that may include the inhibition of cyclooxygenase action, or the synthesis of nitric oxide radicals, or inflammation-related transcription factors $[5,13]$. This heterogeneity might be masking a protective effect for specific NSAIDs with particular pharmacological properties. In vitro studies have suggested that ibuprofen in particular suppresses brain-related inflammation and lowers PD risk [14, 15], and a meta-analysis by Samii et al. [6], which combined results from three epidemiologic studies, noted an inverse association for ibuprofen and PD. It is possible that nondifferential misclassification of ibuprofen use, which was based on prescription use only, biased our effect estimates towards the null. However, a recent publication in this Danish cohort investigating the risk of $\mathrm{PD}$ patients with osteoarthritis, who are typically intensive users of NSAIDs, also suggested no association between prolonged NSAID use and a risk of PD [16].

Lagged analyses are important in our study given that our date of diagnosis does not likely capture the true date of PD onset. In unlagged analyses that included prescriptions dispensed immediately prior to $\mathrm{PD}$ diagnosis, we noted positive associations between PD and nonaspirin NSAIDs, ibuprofen, and acetaminophen use, which is consistent with observations that around the time of diagnosis, PD patients exhibit symptoms that may warrant pain medication use [17]. Analyses that do not lag for an appropriate time prior to diagnosis are therefore likely to capture disease-related pain killer use. This protopathic bias would produce spurious positive associations which may explain previous positive study findings $[18,19]$. 
Our study has several notable strengths. Relying on the Danish registry prescription records helped us avoid recall bias, which has been a problem in some previous studies. Additionally, the Danish registry system provided us with access to a large number of PD patients and controls. However, our study was still limited by a number of issues. First, the national prescription database did not extend back past 1995, thus, we only captured relatively recent usage of prescription medications and were unable to examine different earlier life epochs during which regular usage may have occurred (such as middle age etc.). However, inflammation may perpetuate the degeneration of dopaminergic neurons after an initial insult and anti-inflammatory drugs may be most effective in halting neurodegeneration if taken early and/or consistently throughout the inflammatory process. A study by Langston et al. [20] showed that patients with MPTPinduced parkinsonism exhibited the characteristics of chronic ongoing inflammation in the substantia nigra area as much as 16 years after initial exposure. Furthermore we lagged our primary analyses by 5 years to account for the possible inclusion of prevalent or preclinical cases, and thus we were only able to capture between 1 and 7 years of prescription medications for all subjects. The time period we captured may not reflect a subject's earlier NSAID use, underscoring that our findings only represent the impact of NSAID use at an older age, relatively shortly before PD onset. Additionally, in our study we made the assumption that those redeeming a prescription are in fact taking the medication, which seems to be a more valid assumption for those with repeated prescriptions. We did not estimate the duration of use since this would have required additional assumptions. We lacked smoking data, so used COPD as a proxy for heavy smoking, although COPD is likely not a good proxy for smoking status. Lastly, we expect some nondifferential misclassification of PD diagnoses, which may have led us to miss important associations.

In conclusion, our data do not provide strong evidence for a protective effect of nonaspirin - including ibuprofen - and aspirin NSAIDs, used shortly before diagnosis, in PD. Given evidence of chronic ongoing inflammation years before PD diagnosis, future studies should capture NSAID use decades before PD onset.

\section{Acknowledgment}

This study was supported by National Institutes of Health (NIH) National Institute of Environmental Health Sciences Grants USA (grant No. R01 ES013717).

\section{Disclosure Statement}

The authors report no conflicts of interest.

\section{References}

1 Hirsch EC, Hunot S, Damier P, Faucheux B: Glial cells and inflammation in Parkinson's disease: a role in neurodegeneration? Ann Neurol 1998;44:S115-S120.

- 2 Teismann P, Tieu K, Cohen O, Choi DK, Wu DC, Marks D, Vila M, Jackson-Lewis V, Przedborski S: Pathogenic role of glial cells in Parkinson's disease. Mov Disord 2003;18: 121-129.

- 3 Aubin N, Curet O, Deffois A, Carter C: Aspirin and salicylate protect against MPTP-induced dopamine depletion in mice. J Neurochem 1998;71:1635-1642.

-4 Ferger B, Teismann P, Earl CD, Kuschinsky K, Oertel WH: Salicylate protects against MPTP-induced impairments in dopaminergic neurotransmission at the striatal and nigral level in mice. Naunyn Schmiedebergs Arch Pharmacol 1999;360:256-261.

5 Gagne JJ, Power MC: Anti-inflammatory drugs and risk of Parkinson disease: a metaanalysis. Neurology 2010;74:995-1002.
Samii A, Etminan M, Wiens MO, Jafari S: NSAID use and the risk of Parkinson's disease: systematic review and meta-analysis of observational studies. Drugs Aging 2009;26: 769-779.

7 Mellemkjaer L, Blot WJ, Sorensen HT, Thomassen L, McLaughlin JK, Nielsen GL, Olsen JH: Upper gastrointestinal bleeding among users of NSAIDs: a population-based cohort study in Denmark. Br J Clin Pharmacol 2002;53:173-181.

${ }_{8}$ Friis S, Poulsen AH, Sorensen HT, Tjonneland A, Overvad K, Vogel U, McLaughlin JK, Blot WJ, Olsen JH: Aspirin and other non-steroidal anti-inflammatory drugs and risk of colorectal cancer: a Danish cohort study. Cancer Causes Control 2009;20:731740.

-9 Morrish PK, Rakshi JS, Bailey DL, Sawle GV, Brooks DJ: Measuring the rate of progression and estimating the preclinical period of Parkinson's disease with [18F]dopa PET. J Neurol Neurosurg Psychiatry 1998;64:314-319.
10 Charlson ME, Pompei P, Ales KL, MacKenzie CR: A new method of classifying prognostic comorbidity in longitudinal studies: development and validation. J Chronic Dis 1987;40:373-383.

11 Morris T, Stables M, Hobbs A, de SP, ColvilleNash P, Warner T, Newson J, Bellingan G, Gilroy DW: Effects of low-dose aspirin on acute inflammatory responses in humans. J Immunol 2009;183:2089-2096.

-12 Esposito E, Di Matteo V, Benigno A, Pierucci M, Crescimanno G, Di Giovanni G: Nonsteroidal anti-inflammatory drugs in Parkinson's disease. Exp Neurol 2007;205:295312.

$\checkmark 13$ Asanuma M, Miyazaki I: Nonsteroidal antiinflammatory drugs in Parkinson's disease: possible involvement of quinone formation. Expert Rev Neurother 2006;6:1313-1325. 
14 Asanuma M, Miyazaki I, Ogawa N: Neuroprotective effects of nonsteroidal antiinflammatory drugs on neurodegenerative diseases. Curr Pharm Des 2004;10:695-700.

-15 Casper D, Yaparpalvi U, Rempel N, Werner $\mathrm{P}$ : Ibuprofen protects dopaminergic neurons against glutamate toxicity in vitro. Neurosci Lett 2000;289:201-204.

-16 Rugbjerg K, Friis S, Jørgensen TL, Ritz B, Korbo L, Olsen JH: Risk for Parkinson's disease among patients with osteoarthritis: a Danish cohort study. Mov Disord 2010;25:23552360 .
7 Defazio G, Berardelli A, Fabbrini G, Martino D, Fincati E, Fiaschi A, Moretto G, Abbruzzese G, Marchese R, Bonuccelli U, Del Dotto P, Barone P, De Vivo E, Albanese A, Antonini A, Canesi M, Lopiano L, Zibetti M, Nappi G, Martignoni E, Lamberti P, Tinazzi M: Pain as a nonmotor symptom of Parkinson disease: evidence from a case-control study. Arch Neurol 2008;65:1191-1194.

18 Bornebroek M, de Lau LM, Haag MD, Koudstaal PJ, Hofman A, Stricker BH, Breteler MM: Nonsteroidal anti-inflammatory drugs and the risk of Parkinson disease. Neuroepidemiology 2007;28:193-196.
19 Hernan MA, Logroscino G, Garcia Rodriguez LA: Nonsteroidal anti-inflammatory drugs and the incidence of Parkinson disease. Neurology 2006;66:1097-1099.

20 Langston JW, Forno LS, Tetrud J, Reeves AG, Kaplan JA, Karluk D: Evidence of active nerve cell degeneration in the substantia nigra of humans years after 1-methyl-4-phenyl-1,2,3,6-tetrahydropyridine Ann Neurol 1999;46:598-605. 